\title{
Withdrawn: Rubenstein-Taybi Syndrome with bilateral absence of patella: a case report
}

\section{Sedigheh Ganji-Harsini ${ }^{1}$, Sepide Seydi ${ }^{2}$, Ali Ghanbari ${ }^{1 * *}$, Mostafa Sedighi $^{3}$, Mazyar Khazali ${ }^{3}$ and Mahsa Falahi ${ }^{2, * *}$}

${ }^{1}$ Fertility Infertility Research Center, Kermanshah University of medical sciences, Kermanshah, Iran.*Email: aghanbari@kums.ac.ir.

2Student Research Committee, Kermanshah University of medical sciences, Kermanshah, Iran.**Email: falahi.mahsa@gmail.com.

${ }^{3}$ Department of pediatrics, Kermanshah University of medical sciences, Kermanshah, Iran.

This article has been withdrawn at the request of the correspondent author. The editor apologizes for any inconvenience this may cause.

Received May 16, 2016

Accepted June 25, 2016

Released June 30, 2016

Open Acess Full Text Article

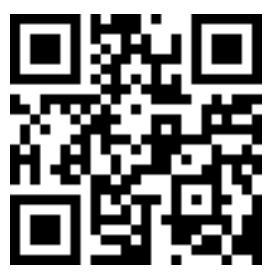

